\title{
Quality of Life in Diabetic Patients in the Primary Care Unit
}

\author{
Thareerat Ananchaisarp, M.D. ${ }^{1}$, Suthida Pringraksa², Jirot Suaiyala², Natnicha Thet-asen², \\ Sirikorn Promvikorn², Suthat Angsawat ${ }^{2}$, Sirapat Pattrapinun ${ }^{2}$, Supanut Punyajirawut ${ }^{2}$
}

${ }^{1}$ Family Medicine Unit, Department of Family and Preventive Medicine, ${ }^{2}$ Medical Student, Faculty of Medicine, Prince of Songkla University, Hat Yai, Songkhla 90110, Thailand.

Received 17 April 2019 • Revised 20 September 2019 • Accepted 28 September 2019 • Published online 1 November 2019

\begin{abstract}
:
Objective: This study aimed to evaluate the level of quality of life and related factors in type 2 diabetic patients who were followed up at the Primary Care Unit of a university hospital in southern Thailand.
\end{abstract}

Material and Methods: A cross-sectional study was conducted in type 2 diabetes patients who were continuously followed up at the primary care unit. Quality of life was the primary outcome assessed by the World Health Organization Quality of Life Brief-Thai questionnaire and related factors were analyzed using the multivariate generalized linear model.

Results: This study included 158 patients who fit our eligibility criteria. The median age was 66 years old and median duration of diabetes was 10 years. Most had comorbidities and a quarter had diabetic complications. The results show $64.6 \%$ of the study sample had a good level of quality of life and no one had a bad level of quality of life. The results of multivariate generalized linear model show that no factors were associated with overall quality of life. Obesity was statistically significantly associated with a lower quality of life in the physical health dimension [odd ratio $(O R)=0.35(0.14,0.89)$, $p$-value $=0.027$ ] and diabetic complications were associated with a lower quality of life in the psychological dimension [OR=0.27 (0.08, 0.85), p-value $=0.025]$.

Conclusion: Most diabetic patients had a good quality of life. There were no factors associated with overall quality of life, but obesity and diabetic complications were statistically significantly associated with some dimensions of quality of life. Healthcare providers should assess aspects of quality of life in patients with chronic diseases.

Keywords: diabetes, primary care, quality of life

Contact: Thareerat Ananchaisarp, M.D.

Department of Family and Preventive Medicine, Faculty of Medicine, Prince of Songkla University, Hat Yai, Songkhla 90110, Thailand.

E-mail: thareerat.a@psu.ac.th

This is an open access article under the CC BY-NC-ND license

(http://www.jhsmr.org/index.php/jhsmr/about/editorialPolicies\#openAccessPolicy).

J Health Sci Med Res 2020;38(1):9-16 doi: 10.31584/jhsmr.201971 www.jhsmr.org 


\section{Introduction}

Diabetes mellitus (DM) is a common disease. The World Health Organization and Thai National Health Examination Survey show an increasing prevalence over the years, as well as an increasing mortality rate. ${ }^{1,2}$ In spite of being a chronic incurable disease, DM has various co-morbidities and many complications, such as hypoglycemia, hyperglycemic crisis, cardiovascular disease, retinopathy, nephropathy and neuropathy. Diabetic patients must adapt their lifestyle, for example, avoiding unhealthy foods. Moreover, diabetic therapy can extremely affect quality of life because of the complexity of treatment regimens or taking insulin. In addition, it may cause financial problems for patients due to medical treatment or travelling expenses. From the above, diabetic patients have a worse quality of life (QOL) than healthy people..$^{3-6}$ The Thai clinical practice guidelines for DM in 2017 recommend healthcare providers evaluate both the QOL and psychological health issues of diabetic patients. ${ }^{7}$

QOL is defined as "an individual's perception of their position in life in the context of the culture and value systems in which they live and in relation to their goals, expectations, standards and concerns. ${ }^{8}$ " QOL consists of 4 dimensions: physical health, psychological health, social interaction and environment. Previous studies show that most type 2 diabetic patients had moderate levels of QOL, while $31.5-41.2 \%$ of patients had good levels of QOL. ${ }^{3-5}$ Questionnaires for the evaluation of QOL can be divided into 2 groups: health-related QOL that assess only the effects from diseases, and holistic QOL that assess all factors of a patient's life. ${ }^{9}$ There are many factors that are statistically significantly associated with QOL in type 2 diabetic patients, such as sex, age, body mass index, duration of disease and having diabetic complications. $^{3-5,10,11}$ Some evidence shows that psychosocial issues are critical to good diabetes care and QOL of diabetic patients indicates the quality of health- care intervention. ${ }^{6}$ Although many studies have reported the prevalence and factors related with QOL, no study has been conducted in the Primary Care Unit (PCU) of Songklanagarind Hospital. The present study aimed to evaluate the level of QOL and related factors in type 2 diabetic patients at the PCU of Songklanagarind Hospital.

\section{Material and Methods \\ Study design and setting}

A cross-sectional study was conducted in the PCU of Songklanagarind Hospital from $8^{\text {th }}$ January 2019 to $2^{\text {nd }}$ February 2019.

\section{Study sample and sampling}

We included type 2 diabetic patients aged more than 20 years who were followed up at the PCU of Songklanagarind Hospital for at least 6 months. Then we excluded patients with a history of cancer because it may affect QOL. The sample size was calculated based on both the objectives of this study. For the first objective, we used the finite population proportion formula that considered the prevalence of good QOL to be $34.0 \%$, based on a previous study ${ }^{3}, 95.0 \%$ confidence interval, a precision error of $5.0 \%$ and 840 type 2 diabetic patients who underwent continuous follow-up at the PCU. For the second objective, we used the Pearson correlation to find the factors related to QOL that considered $r=0.197$ for sex and 0.371 for duration of $\mathrm{DM}^{3}$ with a precision error of $10.0 \%$. The results from both formulas were 79 and 158 persons, respectively. This study enrolled 158 patients who were compatible with the eligibility criteria using the convenience sampling method.

\section{Variables}

The primary outcome was QOL assessed by the World Health Organization Quality of Life Brief-Thai (WHOQOL-BREF-THAI) questionnaire, which is a holistic 
QOL questionnaire. This questionnaire was officially approved by the WHO with a content validity index of 0.6515 and Cronbach's alpha coefficient of $0.8406 .{ }^{12}$ It contains 26 items and each item is rated on a 5-point Likert scale. Total score ranges from 26 to 130 with higher scores indicating a better QOL. Independent variables include characteristics of the patients which previous studies found to be associated with QOL, such as age, sex, body mass index, marital status, duration and control of DM, having complications (retinopathy, nephropathy, neuropathy and cardiovascular diseases) and co-morbidities. Then we added additional factors that we expected to be associated with QOL, such as the ability to undertake the basic activities of daily life and the treatment regimen. The data collection form of this study was sent to 3 professors in order to conduct an Item Objective Congruence (IOC) index of each question; the result showed an $I O C \geq 0.5$ in all questions.

\section{Data collection}

We let participants complete the WHOQOL-BREFTHAI questionnaire by themselves, but researchers read the questionnaire to some participants who requested assistance. Each patient characteristic which may have been associated with QOL was derived from asking patients and confirming the data in the hospital information system.

\section{Data management and analysis}

Data were entered in EpiData (version 3.1, Denmark) with double entry basis and analyzed using the R program (R Core Team 2017, Vienna, Austria). Descriptive statistical analysis was used to analyze the prevalence of $\mathrm{QOL}$ and the baseline characteristics of the patients. We present categorical data in terms of percentage and continuous data in terms of mean \pm S.D. or median with Quartile 1,
Quartile3 (Q1, Q3). We used the Multivariate Generalized Linear Model to test the relations between the associated factors and QOL. A p-value of less than 0.05 was considered statistically significant.

\section{Ethical consideration}

This research was approved by the Ethics Committee of the Faculty of Medicine of Prince of Songkla University. All participants signed informed consent forms after reading the participant information sheet.

\section{Results}

The baseline characteristics of 158 type 2 diabetic patients are shown in Table 1. More than half were female, still working and not obese. The median age was 66 years and duration of having type 2 DM averaged 10 years. All of the participants were physically independent and assessed by the Barthel index of basic activities of daily living. Most of them were not current smokers but had co-morbid diseases. Less than a quarter of them had diabetic complications and used insulin in their treatment regimen. Less than half of them could control their DM within the target range.

Table 1 Patient characteristics $(n=158)$

\begin{tabular}{ll}
\hline Characteristic & \\
\hline Sex & \\
Male & $61(38.6)$ \\
Female & $97(61.4)$ \\
Age (years) [median (Q1, Q3)] & $66.0(59.0,71.6)$ \\
Marital status & \\
Single & $12(7.6)$ \\
Couple & $99(62.7)$ \\
Widow/divorce & $47(29.7)$ \\
Career & \\
No & $77(48.7)$ \\
Yes & $81(51.3)$ \\
\hline
\end{tabular}


Table 1 (continued)

\begin{tabular}{|c|c|}
\hline Characteristic & \\
\hline \multicolumn{2}{|l|}{ Family income (baht per month) } \\
\hline$<5,000$ & $37(23.4)$ \\
\hline $5,000-10,000$ & $36(22.8)$ \\
\hline$>10,000$ & $85(53.8)$ \\
\hline \multicolumn{2}{|l|}{ Current smoking } \\
\hline No & $147(93.0)$ \\
\hline Yes & $11(7.0)$ \\
\hline \multicolumn{2}{|l|}{ Body mass index $\left(\mathrm{kg} / \mathrm{m}^{2}\right)$} \\
\hline$<25$ & $87(55.1)$ \\
\hline$\geq 25$ & $71(44.9)$ \\
\hline \multicolumn{2}{|l|}{ Regular exercise* } \\
\hline No & $72(45.6)$ \\
\hline Yes & $86(54.4)$ \\
\hline Duration of type 2 DM [median (Q1, Q3)] & $10.0(5.0,12.0)$ \\
\hline $\begin{array}{l}\text { Number of medications per day } \\
\text { [median (Q1, Q3)] }\end{array}$ & $6.0(4.0,8.0)$ \\
\hline \multicolumn{2}{|l|}{ Have co-morbid diseases ${ }^{\star *}$} \\
\hline No & $8(5.1)$ \\
\hline Yes & $150(94.9)$ \\
\hline \multicolumn{2}{|l|}{ Have diabetic complications } \\
\hline No & $120(75.9)$ \\
\hline Yes & $38(24.1)$ \\
\hline \multicolumn{2}{|l|}{ Insulin usage } \\
\hline No & $137(86.7)$ \\
\hline Yes & $21(13.3)$ \\
\hline $\begin{array}{l}\text { Fasting blood glucose in last visit [median } \\
\text { (Q1, Q3)] }\end{array}$ & $135.0(121.0,155.8)$ \\
\hline \multicolumn{2}{|l|}{ Disease controlled } \\
\hline Uncontrolled & $81(51.3)$ \\
\hline Well controlled ${ }^{\star \star *}$ & $77(48.7)$ \\
\hline
\end{tabular}

Data are presented as $n(\%)$ unless indicated otherwise.

*regular exercise means aerobic exercise $\geq 30$ minutes per day and $\geq 3$ times per week

**Example of co-morbid diseases were hypertension, dyslipidemia, cardiovascular diseases, chronic kidney disease, etc

${ }^{* * *}$ well controlled consider from assessment of treatment doctor or $\mathrm{HbA}_{1} \mathrm{C}<7.0 \%$ if no data

Q1=Quartile1, Q3=Quartile3, DM=diabetes mellitus
Prevalence of QOL at each level overall and each dimension are shown in Table 2. About two-thirds of the study population had a good level of QOL and the rest had a moderate level; no one had a bad level of overall QOL. When considering each dimension, most of them had both a good level of QOL in psychological and environment health and a moderate level of QOL in physical health and social interaction.

Table 2 Quality of life $(n=158)$

\begin{tabular}{llll}
\hline Quality of life & Good & Moderate & Bad \\
\hline Physical health & $70(44.3)$ & $87(55.1)$ & $1(0.6)$ \\
Psychological health & $108(68.4)$ & $50(31.6)$ & $0(0.0)$ \\
Social interaction & $60(38.0)$ & $90(57.0)$ & $8(5.0)$ \\
Environment & $99(62.7)$ & $59(37.3)$ & $0(0.0)$ \\
Overall & $102(64.6)$ & $56(35.4)$ & $0(0.0)$ \\
\hline
\end{tabular}

Data are presented as $\mathrm{n}(\%)$.

Table 3 shows the multivariate analysis for factors associated with high QOL from an overall aspect. The results showed no factor had an association with overall QOL, but subgroup analysis found some factors statistically significantly associated with some dimensions of QOL as shown in Table 4. In the physical dimension, the diabetic patients who were obese had a statistically significant association with low QOL when compared with patients who had a body mass index $<25 \mathrm{~kg} / \mathrm{m}^{2}$. In the psychological dimension, we found that patients with diabetic complications had a statistically significant association with low QOL. 
Table 3 Multivariate analysis for factors associated with high quality of life in overall aspect in type 2 diabetes mellitus

\begin{tabular}{|c|c|c|c|}
\hline Factor & Crude OR $(95 \% \mathrm{Cl})$ & Adjusted OR $(95 \% \mathrm{Cl})$ & p-value (Wald's test) \\
\hline \multicolumn{4}{|l|}{ Sex } \\
\hline Male & 1 & 1 & \\
\hline Female & $0.71(0.34,1.46)$ & $0.85(0.27,2.69)$ & 0.79 \\
\hline Age (years) & $0.96(0.92,1.00)$ & $0.96(0.91,1.02)$ & 0.22 \\
\hline \multicolumn{4}{|l|}{ Marital status } \\
\hline Couple & 1 & 1 & \\
\hline Single/widow/divorce & $0.93(0.45,1.89)$ & $0.62(0.24,1.63)$ & 0.34 \\
\hline Career & $1.47(0.73,2.96)$ & $1.31(0.48,3.56)$ & 0.60 \\
\hline \multicolumn{4}{|l|}{ Family income (baht per month) } \\
\hline$<5,000$ & 1 & 1 & \\
\hline $5,000-10,000$ & $0.74(0.27,1.99)$ & $0.63(0.17,2.38)$ & 0.50 \\
\hline$>10,000$ & $1.86(0.81,4.45)$ & $1.64(0.46,5.91)$ & 0.45 \\
\hline Obesity (BMI $\geq 25 \mathrm{~kg} / \mathrm{m}^{2}$ ) & $0.79(0.39,1.60)$ & $0.85(0.33,2.15)$ & 0.73 \\
\hline Regular exercise & $1.15(0.57,2.30)$ & $1.40(0.55,3.56)$ & 0.49 \\
\hline Duration of being type $2 \mathrm{DM}$ & $0.97(0.92,1.03)$ & $0.99(0.93,1.07)$ & 0.91 \\
\hline Number of medications per day & $0.93(0.82,1.05)$ & $1.05(0.85,1.29)$ & 0.67 \\
\hline Have co-morbid diseases & $1.34(0.29,6.25)$ & $3.40(0.38,30.72)$ & 0.28 \\
\hline Have diabetic complications & $0.43(0.19,0.96)$ & $0.54(0.18,1.63)$ & 0.27 \\
\hline Insulin usage & $0.52(0.19,1.41)$ & $0.94(0.23,3.93)$ & 0.94 \\
\hline Fasting blood glucose in last visit & $0.99(0.98,1.01)$ & $0.99(0.98,1.01)$ & 0.78 \\
\hline Well controlled of DM & $1.23(0.61,2.46)$ & $0.85(0.28,2.58)$ & 0.77 \\
\hline
\end{tabular}

OR=odd ratio, $\mathrm{Cl}=$ confidence interval, $\mathrm{BMI}=$ body mass index, $\mathrm{DM}=$ diabetes mellitus

Table 4 Multivariate analysis for factors associated with high quality of life in each aspect of quality of life in type 2 diabetes mellitus

\begin{tabular}{|c|c|c|c|c|}
\hline \multirow{2}{*}{ Factor } & \multicolumn{4}{|c|}{ Adjusted OR (95\% Cl) } \\
\hline & Physical health & Psychological health & Social interaction & Environment \\
\hline \multicolumn{5}{|l|}{ Sex } \\
\hline Male & 1 & 1 & 1 & 1 \\
\hline Female & $0.39(0.12,1.23)$ & $1.65(0.49,5.57)$ & $0.76(0.26,2.23)$ & $0.81(0.23,2.92)$ \\
\hline Age & $0.95(0.89,1.01)$ & $0.96(0.91,1.03)$ & $0.97(0.92,1.03)$ & $0.99(0.93,1.05)$ \\
\hline \multicolumn{5}{|l|}{ Marital status } \\
\hline Couple & 1 & 1 & 1 & 1 \\
\hline Single/widow/divorce & $0.86(0.32,2.28)$ & $1.23(0.46,3.27)$ & $0.70(0.28,1.75)$ & $0.45(0.16,1.26)$ \\
\hline Career & $1.35(0.50,3.68)$ & $1.32(0.47,3.71)$ & $0.98(0.38,2.48)$ & $1.01(0.33,3.03)$ \\
\hline \multicolumn{5}{|c|}{ Family income (baht per month) } \\
\hline$<5,000$ & 1 & 1 & 1 & 1 \\
\hline $5,000-10,000$ & $1.32(0.33,5.30)$ & $0.53(0.14,2.03)$ & $1.45(0.36,5.79)$ & $1.46(0.34,6.29)$ \\
\hline$>10,000$ & $0.87(0.22,3.41)$ & $1.68(0.43,6.56)$ & $1.14(0.30,4.28)$ & $1.45(0.37,5.64)$ \\
\hline
\end{tabular}


Table 4 (continued)

\begin{tabular}{lllll}
\hline \multirow{2}{*}{ Factor } & \multicolumn{4}{c}{ Adjusted OR $(95 \% \mathrm{Cl})$} \\
\cline { 2 - 5 } & Physical health & Psychological health & Social interaction & Environment \\
\hline Obesity & $0.35(0.14,0.89)^{*}$ & $0.63(0.25,1.60)$ & $0.88(0.37,2.08)$ & $1.13(0.41,3.14)$ \\
Regular exercise & $0.72(0.27,1.87)$ & $1.47(0.56,3.82)$ & $0.80(0.32,1.98)$ & $1.75(0.63,4.84)$ \\
Duration of being type 2 DM & $1.05(0.97,1.13)$ & $0.97(0.90,1.04)$ & $1.04(0.97,1.12)$ & $0.98(0.91,1.06)$ \\
Number of medications per day & $1.24(1.00,1.54)$ & $1.18(0.94,1.48)$ & $1.05(0.87,1.28)$ & $1.16(0.91,1.46)$ \\
Have co-morbid diseases & $0.55(0.06,4.75)$ & $0.85(0.08,9.47)$ & $10.7(0.72,159.9)$ & $8.42(0.72,98.3)$ \\
Have diabetic complications & $0.45(0.14,1.47)$ & $0.27(0.08,0.85)^{\star}$ & $0.44(0.14,1.39)$ & $0.79(0.22,2.86)$ \\
Insulin usage & $0.37(0.08,1.83)$ & $2.59(0.55,12.17)$ & $1.14(0.29,4.56)$ & $1.59(0.31,7.87)$ \\
Fasting blood glucose in last visit & $0.99(0.98,1.01)$ & $0.99(0.98,1.01)$ & $0.99(0.98,1.01)$ & $0.99(0.97,1.01)$ \\
Well controlled of DM & $1.46(0.46,4.64)$ & $0.83(0.27,2.61)$ & $1.48(0.49,4.44)$ & $1.05(0.32,3.43)$ \\
\hline
\end{tabular}

$\mathrm{QOL}=$ quality of life, $\mathrm{OR}=$ odd ratio, $\mathrm{Cl}=$ confidence interval, $\mathrm{DM}=$ diabetes mellitus ${ }^{*}$ p-value (Wald's test) $<0.05$

\section{Discussion}

The majority of diabetic patients at the primary care unit of a university hospital in southern Thailand had good QOL. No factors were associated with overall QOL. However, obesity was associated with low QOL in the physical dimension and having diabetic complications was associated with low QOL in the psychological dimension.

Most of the diabetic patients in this study had a good QOL, while in the previous study they had a moderate QOL. ${ }^{3,5}$ It may be due to the population in this study having had higher family incomes and fewer complications, which made the patients less anxious about expenditures and effects from complications, resulting in a higher QOL. When considering each dimension, in psychological and environment health, most of the diabetic patients had a good level of QOL, while in the physical health and social interaction dimension most of them had a moderate level of QOL. This finding is the same as in the previous study. ${ }^{3}$

Although this study did not find any factors associated with overall QOL, as previous studies had, ${ }^{3-5,10,11,13}$ it may be due to the fact that the sample size was too small to demonstrate the association of known risk factors and QOL (power=36.7\%). But we did find that some factors had statistically significant associations with some dimensions of QOL. First, we found one factor statistically significantly associated with QOL in the physical dimension, which was BMI. Diabetic patients who had a body mass index $<25 \mathrm{mg} / \mathrm{m}^{2}$ were associated with a higher QOL in the physical dimension, which is consistent with previous research which found that an increasing body mass index in the elderly is associated with chronic disease or an increasing severity of underlying disease. ${ }^{14}$ This forces patients to limit daily activities, causing a decrease in QOL in physical health. Another factor: having diabetic complications was statistically significantly associated with low QOL in the psychological dimension; this result is in accordance with Rubin's paper reviews. ${ }^{6}$ It may be able to explain that having diabetic complications causes stress, anxiety or a decreasing satisfaction in life.

The strengths of this study: it is one of only a few studies on this topic in southern Thailand. The results are 
interesting and useful for healthcare providers. Moreover, this study included some factors which had not been investigated in previous research. There are some limitations in this study. First, this study used the WHOQOL questionnaire to assess QOL. This tool was pilot studied in subjects less than 60 years old. Thus, this questionnaire may be too complicated for elderly patients. In order to cope with this limitation, we clarified the meaning of questions for the elderly patients who couldn't understand some parts of the questionnaire. The next limitation: this study was conducted in the primary care unit of a university hospital. Therefore, the results can't be applied to other hospital settings. The other limitation: a crosssectional study can determine only associations; it cannot determine causal relationships between factors and QOL. Lastly, due to populations in the study that we used to calculate sample size for this study may difference from populations in this study, cause difference in relationship between quality of life and related factors. Therefore, the sample size calculated from the formula may not have been large enough to test the relationships in this study.

\section{Suggestions}

The results should be used to plan treatment strategies for improving patient care and follow-up in order to improve the quality of life in diabetic patients. In addition, healthcare providers should pay attention to the assessment and care aspects of quality of life in patients with chronic diseases. For further study, we suggest extending the study setting to other clinics and increasing the sample size for testing the relationship between quality of life and related factors.

\section{Conclusion}

Most of the diabetic patients had a good quality of life. There were no factors associated with overall QOL.
However, obesity was associated with a low QOL in the physical dimension and having diabetic complications was associated with a low QOL in the psychological dimension with statistical significance.

\section{Acknowledgement}

We greatly appreciate the assistance of Pitchayanont Ngamchaliew, Panya Chamroonkiadkun and Chonnakarn Jatchavala for doing the Item Objective Congruence index for our data collection form. We also thank Kittisakdi Choomalee for data analysis and Mr. Trevor Pearson for his assistance in editing the English language of this paper.

\section{Conflict of interest}

No

\section{References}

1. Aekplakorn W. Thai national examination survey V. 2014 [monograph on the Internet]. Bangkok: NHESO; 2014 [cited 2018 Nov 30]. Available from: http://thaitgri.org/?p=37869

2. World Health Organization. Global report on diabetes [monograph on the Internet]. Geneva: WHO; 2016 [cited 2019 Jan 12]. Available from: https://apps.who.int/iris/bitstream/handle/ 10665/204871/9789241565257_eng.pdf;jsessionid= 43AB4673958329ECF35DC176E95AF355? sequence $=1$

3. Srichaijaroonpong $S$, Petchwisai $A$, Paisan R. Factors relating to the quality of life of the diabetic patients at Ban Chiang Kruea Pho Chai health promoting hospital, Chiang Kruea sub district, Muang district, Sakon Nakorn province. J Office DPC 7 Khon Kaen. 2016;3:23-33.

4. Prajapati VB, Blake R, Acharya LD, Seshadri S. Assessment of quality of life in type II diabetic patients using the modified diabetes quality of life (MDQoL)-17 questionnaire. Braz J Pharm Sci 2017;53:e17144.

5. Pragodpol P, Suwannaka Y, Chaiyarit A, Sosome B, Sritan S, Sroisrisawasd $M$, et al. Levels of quality of life and method to develop quality of life in thai chronically ill patients [monograph on the Internet]. Bangkok: HSRI Knowledge Bank; 2015 [cited 2019 Jan 1]. Available from: http://kb.hsri. or.th/dspace/handle/11228/4371?locale-attribute=en 
6. Rubin RR, Peyrot M. Quality of life and diabetes. Diabetes Metab Res Rev 1999;15:205-18.

7. Diabetes Association of Thailand. Clinical practice guideline for diabetes [homepage on Internet]. Bangkok: DAT; 2017 [cited 2019 Jan 1]. Available from: www.lpnh.go.th/newlp/ wp-content/uploads/2013/10/CPG-2560-25-7-60-A5.pdf

8. World Health Organization. WHOQOL: measuring quality of life [homepage on the Internet]. Geneva: WHO; 2018 [cited 2018 Dec 1]. Available from: http://www.who.int/healthinfo/ survey/whoqol-qualityoflife/en/

9. Trevittaya P. Concepts of quality of life. Bull Chiang Mai Assoc Med Sci 2016;49:171-84.

10. Konsantia S. Quality of life of diabetic mellitus persons: a case study at Muangyang Hospital, Nakhonratchasima. J Boromarajonani Coll Nurs Nakhonratchasima 2011;17:31-44.
11. Kiadaliri AA, Najafi B, Mirmalek-Sani M. Quality of life in people with diabetes: a systematic review of studies in Iran. J diabetes Metab Disord 2013;12:54.

12. Department of Mental Health. WHOQOL-BREF-THAI Questionaire [homepage on the Internet]. Bangkok: Department of Mental Health; 2002 [cited 2018 Nov 30]. Available from: https://www.dmh.go.th/test/download/view.asp?id=17

13. Solli O, Stavem K, Kristiansen IS. Health-related quality of life in diabetes: the associations of complications with EQ-5D scores. Health Qual Life Outcomes 2010;8:18.

14. Lee G, Park J, On SW, Joh HK, Hwang SS, Kim J, et al. Association between body mass index and quality of life in elderly people over 60 years of age. Korean J Fam Med 2017; 38:181-91. 